\title{
Prevalence of Diabetes and Cardiovascular Comorbidity in the Canadian Community Health Survey 2002-2003
}

\author{
Frank Mo*, Lisa M. Pogany, Felix C.K. Li, and Howard Morrison \\ Centre for Chronic Disease Prevention and Control, Public Health Agency of \\ Canada, Government of Canada, 120 Colonnade Road, Ottawa, Ontario, K1A OK9 \\ Canada \\ E-mail: Frank Mo@phac-aspc.gc.ca
}

Received March 17, 2005; Revised May 11, 2005; Accepted May 11, 2005; Published January 24, 2006

Diabetes mellitus is a major risk factor for heart disease (heart attack, angina, and heart failure), stroke, and hypertension, which shorten the average life expectancy. The main objective of this study was to describe the prevalence of heart disease, hypertension, and stroke among Canadians with diabetes compared to those without diabetes in the Canadian general population aged 12 years and over. It also estimated the strength of association between diabetes, heart disease, hypertension, and other factors such as age, gender, cigarette smoking, alcohol drinking, education status, body mass index (BMI), and other socioeconomic factors.

Descriptive statistics were used initially to estimate the prevalence of related comorbidities by age and gender. Logistic regression was then employed to determine the potential strength of association between various effects. Data included 127,610 individuals who participated in the 2.1 cycles of the Canadian Community Health Survey (CCHS) in 2002-2003.

The prevalence of self-reported hypertension, heart disease, and stroke among individuals with diabetes were $51.9,21.7$, and $4.8 \%$, respectively. By comparison, prevalence among those without diabetes was 12.7, 4.2, and $0.9 \%$. Adjusted Odds Ratios (OR) were $4.15,5.04$, and 6.75 for males', and 4.10, 5.29, and 4.56 for females' hypertension, heart disease, and stroke, respectively. Lower income (OR from 1.27-1.94) and lower education (OR from 1.23-1.86) were independently associated with a high prevalence of hypertension, heart disease, and stroke among diabetics. Alcohol consumption (OR from 1.06-1.38), high BMI (OR from 1.17-1.40), physical inactivity (OR from 1.21-2.45), ethnicity, and immigration status were also strongly associated with hypertension, heart disease, and stroke.

The adjusted prevalence of hypertension, heart disease, and stroke in the CCHS-2003 health survey in Canada was significantly higher among those with diabetes compared to those without. Other factors such as age, gender, BMI, lifestyle, family incomes, physical activity levels, and socioeconomic status also affected the strength of association between diabetes and resulting comorbidities.

KEYWORDS: diabetes, comorbidity, hypertension, stroke, heart disease, risk factors, lifestyle, social economics, health survey, epidemiology, public health, human development, Canada 


\section{INTRODUCTION}

Diabetes mellitus is the seventh leading cause of death in Canada, affects more than 2 million Canadians, and may shorten life expectancy by up to 15 years[1,2]. The risk for heart disease and stroke among individuals with diabetes, compared to those without, is about four- to sixfold higher and approximately $50 \%$ of adults with diabetes have high blood pressure[3]. In a recent study from Germany, severe complications were diagnosed in $50 \%$ of diabetes patients including myocardial infarction, stroke, foot ulcer, amputations, and blindness[4].

The lifetime costs associated with comorbidities of diabetes mellitus are substantial in Canada; the cost of diabetes was estimated to be $\$ 1.6$ billion in 1998, an increase of $45 \%$ from the estimate of $\$ 1.1$ billion in 1993[5] and is likely to be $\$ 19.2$ billion in 2020[6]. Direct medical costs of managing complications from diabetes average $\$ 47,240$ per patient over 30 years (in 2000 U.S. dollars)[7]. More severe or debilitating events generate a greater financial burden than do early-stage complications and complications that are initially relatively low in cost can progress to more costly advanced stages[8]. This significant reduction of life span and quality of life, along with the financial costs of diabetes, suggest that action is required for prevention and control of complications of diabetes[1].

The overall picture of cardiovascular comorbidities of diabetes in the general Canadian population is likely to be similar to other developed countries, however, there have not been specific Canadian population estimates among age and sex subpopulations. Further, the role of health behaviors and socioeconomic status on cardiovascular comorbidities is unknown. Evidence-based guidance for control and management in the context of multiple comorbid conditions and complications in hospital settings is required.

The objectives of this study were to describe self-reported comorbidities among diabetics compared to nondiabetics using the Canadian Community Health Survey (CCHS) of 2002-2003, and to assess the impact of health behaviors and socioeconomic status on cardiovascular comorbidities.

\section{METHODS}

\section{Canadian Community Health Survey}

The Canadian Community Health Survey (CCHS) of 2002-2003[9] is a collaborative effort between Statistics Canada, Health Canada, and the Canadian Institute for Health Information. This survey was created to gather health-related data at subprovincial levels in order to provide timely cross-sectional estimates of health determinants, health status, and health system utilization. The CCHS began collecting data in September of 2000 and the data collection was based on a 2-year collection cycle.

\section{Sampling}

Each of the collection cycles is comprised of two distinct surveys: a health region-level survey in the first year with a total sample of 130,000 and a provincial-level survey in the second year with a total sample of 30,000. The target population for the CCHS 2003 was household residents in all Canadian provinces and territories; with the exclusion of Canadian Forces Bases and some remote areas. One member of each household sample was selected with a second member of certain households being sampled in order to oversample for youths.

\section{Measures of Diabetes and Comorbidity}

Diabetes was identified by self-report based on the question "Has your doctor ever said that you had diabetes?" The comorbidities, also diagnosed by self-report, were in response to the question "Has 
(comorbidity) lasted or expected to last 6 months or more and was it diagnosed by a health professional?" The comorbidities inquired about by the CCHS-2003 questionnaire included allergy, asthma, arthritis or rheumatism, back problem, high blood pressure, migraine headaches, chronic bronchitis or emphysema, sinusitis, epilepsy, heart disease, cancer, stomach or intestinal ulcers, effects of a stroke, urinary incontinence, bowel disorder, dementia, cataracts, glaucoma, and thyroid condition.

\section{Measures of Diabetes Covariate Variables}

The self-reported covariates included in this analysis were age, gender, area of residence, body mass index (BMI), physical activity, socioeconomic status (income, ethnicity, immigration, education), smoking status (former smokers, current smokers, and never smokers), and heavy alcohol intake. BMI was calculated from the equation BMI $=$ weight $(\mathrm{kg}) /$ height $(\mathrm{m})^{2}$. Physical activity was grouped as active, moderate, and inactive based on leisure time energy expenditure[5]. Education was grouped into three levels based on the years of education individual gains: less than secondary school education, which indicated not finishing 12 years of basic education; secondary school education completed; and postsecondary school education. Physically active was defined as an energy expenditure of at least 3 KKD (kilocalories per kilogram of body weight per day), moderately active corresponds to an energy expenditure between 1.5 and $3 \mathrm{KKD}$, while physically inactive is defined as less than $1.5 \mathrm{KKD}$. Income adequacy was classified into low, low middle, upper middle, and high-income groups on the basis of total household income and the number of household members[10,11]. Ethnicity included Canadian and other minority origins. Immigration status includes Canadians that were born in Canada or immigrated from overseas. These definitions have been used in previous studies of similar Canadian data[12,13,14,15,16,17].

\section{Data Analysis}

Descriptive statistics were used initially to estimate the prevalence of diabetes and its related comorbidities by age and gender. Logistic regression was then employed to determine the potential strength of association between various effects. Data included 127,610 individuals who participated in the 2.1 cycle of the Canadian Community Health Survey (CCHS) in 2002-2003. The logistic regression models were adjusted in order to take the design effects of the CCHS-2003 into account. These techniques have been used by in previous analyses of the national hospitalization data[18] and the NPHS data[12,13,14,15,16,17].

\section{RESULTS}

The overall prevalence of self-reported diabetes mellitus in the CCHS-2003 cohort was $4.9 \%$ for males and $4.3 \%$ for females (Table 1), and the risk of diabetes was higher among males than females (Table 2). The prevalence of diabetes increased with increasing age and was most prevalent in those individuals over 65 years of age ( $13.5 \%$ for both sexes combined [Table 1]).

The cardiovascular comorbidities of hypertension, heart disease, and stroke were more prevalent among diabetics compared to nondiabetics (51.9 vs. $12.7 \%$ [OR $=4.12$; 95\% CI 4.05-4.19], 21.7 vs. $4.2 \%[\mathrm{OR}=5.16 ; 95 \% \mathrm{CI} 5.12-5.23]$, and 4.8 vs. $0.9 \%$ [OR $=5.99 ; 95 \%$ CI 5.91-6.13], respectively [Table 2]). (OR, Odds Ratio; CI, Confidential Interval) 
TABLE 1

Distribution of Personal, Risk Factors, and Socioeconomic Characteristics by Diabetic Status Among Canadians 12 Years of Age and Over (CCHS, Canada, 2003)*

\begin{tabular}{|c|c|c|c|c|}
\hline & \multicolumn{2}{|c|}{ Diabetic Sample $(n=7,353)$} & \multicolumn{2}{|c|}{ Nondiabetic Sample $(n=120,149)$} \\
\hline & $\mathbf{n}$ & $\%$ & $\mathbf{n}$ & $\%$ \\
\hline \multicolumn{5}{|l|}{ Sex } \\
\hline Males & 3,521 & 4.9 & 54,892 & 95.1 \\
\hline Females & 3,832 & 4.3 & 65,257 & 95.7 \\
\hline \multicolumn{5}{|l|}{ Age group (years) } \\
\hline $12-34$ & 338 & 0.7 & 42,261 & 99.3 \\
\hline $35-64$ & 3,335 & 4.9 & 54,984 & 95.1 \\
\hline 65 and over & 3,680 & 13.5 & 22,904 & 86.5 \\
\hline \multicolumn{5}{|l|}{ Overweight or obese (BMI) } \\
\hline$=<25$ & 2,023 & 28.0 & 67,929 & 64.8 \\
\hline $26-29$ & 1,789 & 32.2 & 23,321 & 21.4 \\
\hline$=>30$ & 2,652 & 39.8 & 16,672 & 13.8 \\
\hline \multicolumn{5}{|l|}{ Family Income } \\
\hline High income quartile & 1,272 & 22.3 & 12,416 & 37.6 \\
\hline Upper middle income quartile & 2,017 & 33.0 & 22,255 & 34.5 \\
\hline Low middle income quartile & 1,974 & 30.4 & 36,067 & 19.2 \\
\hline Low income quartile & 1,053 & 14.2 & 31,614 & 8.8 \\
\hline \multicolumn{5}{|l|}{ Immigrant Status } \\
\hline Immigrants & 1,102 & 26.2 & 15,101 & 20.2 \\
\hline Non mmigrants & 6,119 & 73.8 & 103,075 & 79.8 \\
\hline \multicolumn{5}{|l|}{ Physical activity } \\
\hline Active & 1,158 & 17.5 & 32,573 & 27.5 \\
\hline Moderate & 1,495 & 22.1 & 29,285 & 25.2 \\
\hline Inactive & 4,392 & 60.4 & 55,798 & 47.3 \\
\hline \multicolumn{5}{|l|}{ Education Level } \\
\hline Postsecondary & 3,713 & 62.3 & 82,923 & 78.7 \\
\hline Secondary & 974 & 13.4 & 16,827 & 12.4 \\
\hline Less than secondary & 2,361 & 24.3 & 19,254 & 8.9 \\
\hline \multicolumn{5}{|l|}{$\begin{array}{l}\text { Heavy alcohol drinking (once } \\
\text { per week or everyday) }\end{array}$} \\
\hline Yes & 1,713 & 57.2 & 44,603 & 48.0 \\
\hline No & 2,667 & 42.8 & 45,897 & 52.0 \\
\hline \multicolumn{5}{|l|}{ Smoker Status } \\
\hline Never & 2,032 & 16.1 & 42,664 & 37.5 \\
\hline Former & 4,035 & 52.7 & 48,146 & 39.0 \\
\hline Current & 1,265 & 31.2 & 28,991 & 23.5 \\
\hline \multicolumn{5}{|l|}{ Ethnicity } \\
\hline First Nations & 1,550 & 19.3 & 25,514 & 20.1 \\
\hline English origin & 1,518 & 17.5 & 22,618 & 16.3 \\
\hline French origin & 1,201 & 13.8 & 19,821 & 15.1 \\
\hline Other origin & 3,084 & 49.4 & 52,196 & 48.5 \\
\hline
\end{tabular}

* Counts unweighted; percent weighted. 
TABLE 2

Prevalence (\%) of Self-Reported Cardiac Comorbidities Among Diabetes Compared to Nondiabetics by Sex Among Canadians 12 Years of Age and Over (CCHS, Canada, 2003)

\begin{tabular}{lcccccc}
\hline \multirow{2}{*}{ Diabetes Status } & \multicolumn{2}{c}{ With Diabetes } & \multicolumn{2}{c}{ Without Diabetes } & \multicolumn{2}{c}{ Diabetes Status Difference } \\
\cline { 2 - 7 } & $\mathbf{n}$ & \%* $^{*}$ & $\mathbf{n}$ & \%* $^{*}$ & OR $^{* *}$ & $\mathbf{9 5 \% ~ C l ~}$ \\
\hline Hypertension (Yes) & & & & & & \\
Overall & 4,044 & 52.1 & 18,618 & 12.7 & 4.12 & $4.05-4.19$ \\
Males & 1,749 & 48.5 & 7,337 & 11.7 & 4.15 & $4.10-4.21$ \\
Females & 2,295 & 55.7 & 11,281 & 13.6 & 4.10 & $4.04-4.16$ \\
Heart disease (Yes) & & & & & & \\
Overall & 1,719 & 21.7 & 6,802 & 4.2 & 5.16 & $5.12-5.23$ \\
Males & 842 & 23.2 & 3,307 & 4.6 & 5.04 & $4.91-5.14$ \\
Females & 877 & 20.1 & 3,495 & 3.8 & 5.29 & $5.20-5.38$ \\
Stroke (Yes) & & & & & & \\
Overall & 399 & 4.8 & 1,340 & 0.8 & 5.99 & $5.91-6.13$ \\
Males & 200 & 5.4 & 611 & 0.8 & 6.75 & $6.67-6.83$ \\
Females & 199 & 4.1 & 729 & 0.9 & 4.56 & $4.47-4.68$ \\
\hline
\end{tabular}

* Percent weighted. ** Controlled for age.

\section{Relationship Between Gender on Cardiovascular Comorbidities}

Female diabetics were more likely than male diabetics to report hypertension, but male diabetics were more likely than females to report heart disease or stroke (Table 2). Among males and females, respectively, hypertension was reported by half of diabetics ( 48.5 vs. $55.7 \%$, respectively) compared to 11.7 and $13.6 \%$ of nondiabetics, respectively $(\mathrm{OR}=4.15 ; 95 \% \mathrm{CI} 4.13-4.17$ and $\mathrm{OR}=4.10 ; 95 \% \mathrm{CI}$ 4.08-4.12 for males and females, respectively). Overall, female diabetics were more likely to report hypertension than male diabetics ( $\mathrm{OR}=1.14 ; 95 \% \mathrm{CI} 1.12-1.15)$.

Heart disease was reported less frequently than hypertension at under one-quarter of male and female diabetics compared to less than $5 \%$ of their peers $(\mathrm{OR}=5.04 ; 95 \%$ CI $5.01-5.08$ and $\mathrm{OR}=5.29 ; 95 \% \mathrm{CI}$ 5.26-5.31 for males and females, respectively). However, once adjusted for age, females were more likely to report awareness of heart disease $(\mathrm{OR}=1.15 ; 95 \%$ CI 1.13-1.16) (Table 2).

Lastly, stroke was more common among male and female diabetics compared to their peers (5.4 vs. $0.8 \%[\mathrm{OR}=6.75 ; 95 \%$ CI $6.72-6.79]$ and 4.1 vs. $0.9 \%$ [OR $=4.56 ; 95 \%$ CI $4.53-4.59]$, respectively). Overall, male diabetics were more likely to report a history of stroke compared to female diabetics $(\mathrm{OR}=$ 1.32; 95\% CI 1.30-1.35) (Table 2).

\section{Relationship Between Health Behaviors on Cardiovascular Comorbidities}

Among diabetics, the odds of reporting a cardiovascular comorbidity varied by a number of known risk factors. Compared to diabetics reporting a healthy BMI $(\leq 25)$, those reporting increased BMI $(\geq 30)$ also reported hypertension (42.4 vs. 59.5\% [OR $=1.40 ; 95 \%$ CI $1.38-1.43])$, heart disease $(29.3$ vs. $40.9 \%$ $[\mathrm{OR}=1.17 ; 95 \% \mathrm{CI} 1.15-1.19]$ ), and stroke (4.1 vs. 5.1\% $[\mathrm{OR}=1.24 ; 95 \%$ CI $1.22-1.26])$ more frequently (Table 3). Similarly, all cardiovascular comorbidities were reported more frequently among diabetics who reported alcohol consumption (OR from 1.06-1.38), current and former smokers (OR from 1.12-1.38), and those who were physically inactive (OR from 1.21-2.45) (Table 3). 
TABLE 3

OR and $95 \% \mathrm{Cl}$ of Awareness of Cardiac Comorbidities Among Diabetics by Risk Factors Among Canadians 12 Years of Age and Over (CCHS, Canada, 2003)*

\begin{tabular}{|c|c|c|c|c|c|c|c|c|c|c|c|c|}
\hline & \multicolumn{4}{|c|}{ Hypertension } & \multicolumn{4}{|c|}{ Heart Disease } & \multicolumn{4}{|c|}{ Stroke } \\
\hline & $\mathbf{n}$ & $\%$ & OR & $95 \% \mathrm{Cl}$ & $\mathbf{n}$ & $\%$ & OR & $95 \% \mathrm{Cl}$ & $\mathbf{n}$ & $\%$ & OR & $95 \% \mathrm{Cl}$ \\
\hline \multicolumn{13}{|l|}{ BMI } \\
\hline$=<25$ & 935 & 42.4 & 1.00 & - & 451 & 29.3 & 1.00 & - & 111 & 4.1 & 1.00 & - \\
\hline $26-29$ & 978 & 52.2 & 1.23 & $1.21-1.25$ & 452 & 34.8 & 1.13 & $1.12-1.14$ & 97 & 4.2 & 1.02 & $1.01-1.03$ \\
\hline$=>30$ & 1,650 & 59.5 & 1.40 & $1.38-1.43$ & 592 & 40.9 & 1.17 & $1.15-1.19$ & 136 & 5.1 & 1.24 & $1.22-1.26$ \\
\hline \multicolumn{13}{|l|}{$\begin{array}{l}\text { Heavy } \\
\text { alcohol } \\
\text { drinking }\end{array}$} \\
\hline No & 887 & 48.7 & 1.00 & - & 324 & 16.2 & 1.00 & - & 71 & 3.8 & 1.00 & - \\
\hline Yes & 1,440 & 50.6 & 1.04 & 1.03-1.06 & 565 & 19.2 & 1.19 & $1.17-1.23$ & 122 & 4.2 & 1.11 & $1.10-1.13$ \\
\hline \multicolumn{13}{|l|}{$\begin{array}{l}\text { Smoker } \\
\text { Status }\end{array}$} \\
\hline Never & 1,176 & 31.7 & 1.00 & - & 447 & 5.9 & 1.00 & - & 111 & 3.0 & 1.00 & - \\
\hline Former & 2,281 & 55.1 & 1.03 & $1.02-1.04$ & 1,025 & 24.8 & 1.28 & $1.26-1.31$ & 226 & 5.4 & 1.35 & $1.32-1.37$ \\
\hline Current & 575 & 39.5 & 1.12 & $1.10-1.13$ & 241 & 16.2 & 1.35 & $1.32-1.37$ & 61 & 4.5 & 1.38 & $1.35-1.41$ \\
\hline \multicolumn{13}{|l|}{$\begin{array}{l}\text { Physical } \\
\text { activity }\end{array}$} \\
\hline Active & 557 & 45.0 & 1.00 & - & 202 & 15.5 & 1.00 & - & 32 & 2.0 & 1.00 & - \\
\hline Moderate & 794 & 49.5 & 1.10 & $1.09-1.12$ & 270 & 17.1 & 1.10 & $1.09-1.12$ & 60 & 3.6 & 1.80 & $1.78-1.83$ \\
\hline Inactive & 2,524 & 54.3 & 1.21 & $1.19-1.23$ & 1,141 & 24.5 & 1.58 & $1.55-1.60$ & 244 & 4.9 & 2.45 & $2.41-2.48$ \\
\hline
\end{tabular}

* Controlled for age, sex, and the all variables of family income, immigrant status, ethnicity, and education levels.

\section{Relationship Between Age and Cardiovascular Comorbidities}

Age should impact the cardiovascular comorbidities. In the 65 years and over age group, the cardiac comorbidities were about three- to sevenfold higher as compared to the 12-34 year age group (OR from 3.39-7.86) (Table 4).

\section{Relationship Between Socioeconomic Status and Cardiovascular Comorbidities}

Several socioeconomic indicators were associated with an increased prevalence and risk of comorbidity in a diabetic population. These included having a low income (OR from 1.14-1.85), being nonimmigrants (OR from 1.08-1.35), English origin (OR from 1.01-1.28), and having an education of less than secondary school (OR from 1.23-1.86) (Table 4).

\section{DISCUSSION}

Diabetes mellitus and its comorbidities such as hypertension, heart disease, and stroke share several important characteristics, particularly their association with obesity, physical inactivity, cigarette smoking, and heavy alcohol drinking, and both appear to be modifiable through changing these risk factors[19,20]. Cardiovascular disease is the most important cause of mortality among diabetic patients[21]. Activated immunity and cytokine production lead to insulin resistance and other components 
TABLE 4

OR and 95\% Cl of Awareness of Cardiac Comorbidities Among Diabetics by Socioeconomic Status Among Canadians 12 Years of Age and Over (CCHS, Canada, 2003)*

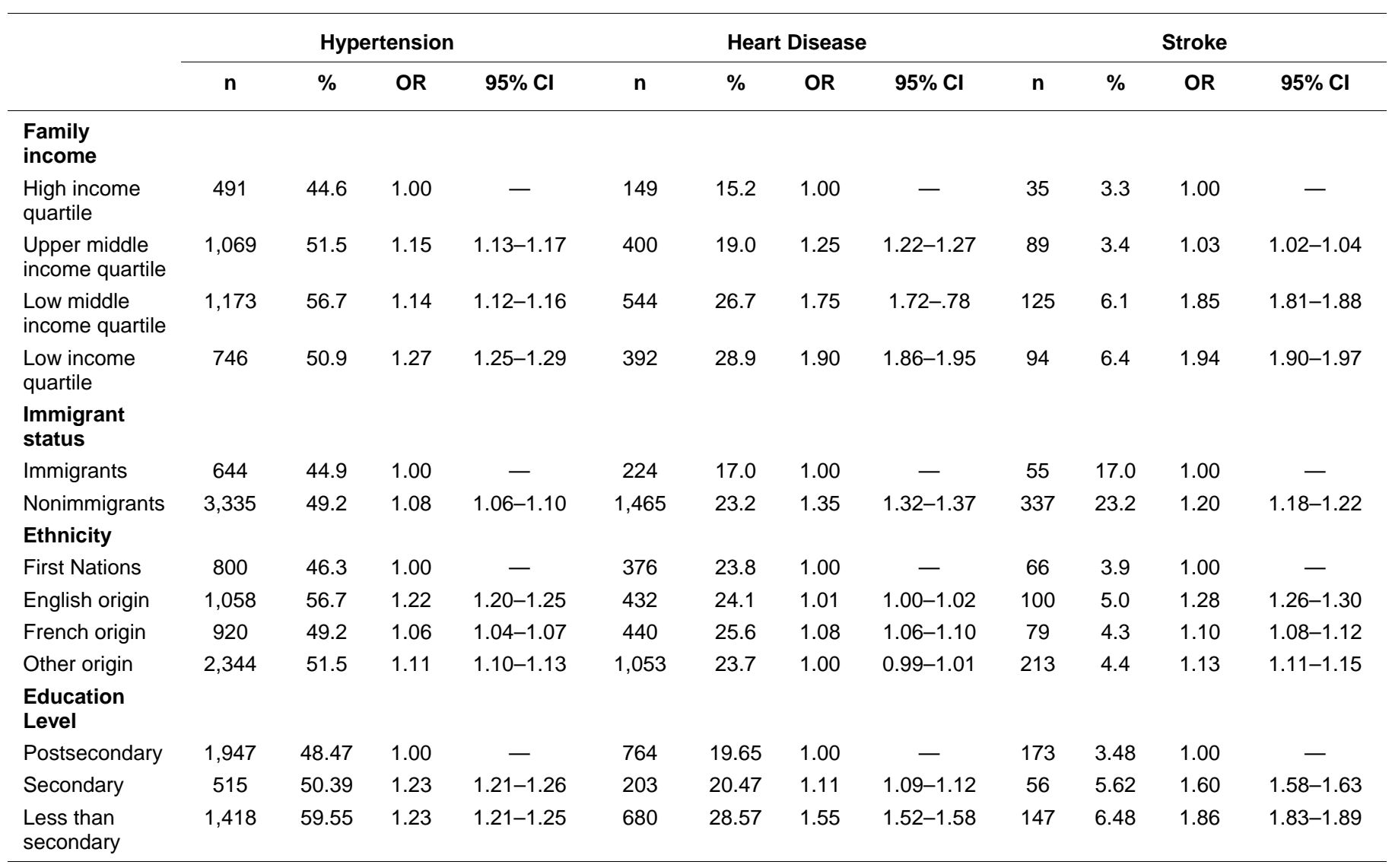

* Controlled for age, sex, and the all variables of risk factors (overweight, heavy alcohol drinking, cigarette smoking, and physical activity).

of the metabolic syndrome, establishing the link between diabetes and arteriosclerosis, which accounts for about $80 \%$ of all deaths from diabetes, of which $75 \%$ are attributable to cardiovascular disease[22]. The present study examined the prevalence of both shared risk factors for cardiovascular disease and diabetes in a diabetic population, as well as the prevalence and risk of one or more cardiac comorbidities within diabetic patients.

The elevated risk of cardiac comorbidities has been previously reported, but our quantification of risk of these comorbidities using odds ratios is unique among the majority of the literature. It is important to note that while hypertension was the most prevalent comorbidity, risk of heart disease was the most increased as compared to the control group. The prevalence of each comorbidity increased in the diabetic patients as age increased, suggesting that addressing the shared risk factors at a younger age may prevent some of the prevalence in later life.

BMI has been previously associated with both diabetes and cardiovascular disease $[23,24,25,26$, 27,28]. This study demonstrates a clear link between the development of cardiac comorbidities within a diabetic population when the subjects BMI is greater than 25. This is important in that it provides a quantitative link between diabetes, BMI, and cardiovascular disease, which reaffirms the importance of risk factor modification, particularly BMI, once diabetes has been diagnosed in order to prevent cardiac comorbidities, which often lead to early death. 
Within the diabetic population, people who abstain from alcohol drinking and quit cigarette smoking were at a lower risk of diabetic comorbidities, suggesting again the need to modify this behavior after the onset of diabetes to prevent associated morbidity and mortality.

Both cardiovascular disease and diabetes have been associated with low socioeconomic status (SES)[29,30,31,32]. The current study shows that people with diabetes, who are of low SES, are more likely to develop a diabetic comorbidity as compared to more affluent people with diabetes. The reasons for this reduced risk in affluent populations are unclear and could range from better health care, access to information about risk behavior modification, or other unknown factors.

The current study adds to the literature that links cardiac diseases and diabetes. As well, it demonstrates, quantitatively, the increase in risk that people with diabetes have in developing cardiovascular disease as compared to a normal population. The increase in risk of diabetic comorbidities as a result of shared risk factors suggests that an intervention targeted at those risk factors within a diabetic population may be vital to reduce the high cost of mortality resulting from diabetic complications. As well, it has recently been postulated that diabetes has a multiplicative interaction with traditional cerebrovascular and cardiovascular disease risk factors, which result in an increase in overall vascular risk when additional risk factors for cardiovascular disease are present in the diabetic patient[33].

This study has several limitations including an issue with self-report. Therefore, there may be misreporting in both the case and control population.

\section{CONCLUSIONS}

The adjusted prevalence of diabetes and its comorbid hypertension, heart disease, and stroke in the CCHS-2003 data was significantly higher among those with diabetes compared to those without. Other factors such as age, gender, BMI, lifestyle, family incomes, health service utilization, and socioeconomic status also affected the strength of association between diabetes and resulting comorbidities and complications.

\section{REFERENCES}

1. Health Canada (2002) Diabetes in Canada. Health Canada, Ottawa.

2. Health Canada (1999) Diabetes in Canada. National Statistics and Opportunities for Improved Surveillance, Prevention, and Control. Cat. No. H49-121. Diabetes Division, Bureau of Cardio-respiratory Disease and Diabetes, Laboratory Centre for Disease Control, Health Protection Branch, Ottawa.

3. Srimahachota, S., Boonyaratavej, S., Udayachalerm, W., Buddhari, W., Somabutr, C., Chayanont, D., and Ngarmukos, P. (2001) Initial outcomes of coronary angioplasty in diabetic patients. J. Med. Assoc. Thai. 84(Suppl 1), S437-442.

4. $\quad$ Liebl, A., Neiss, A., Spannheimer, A., Reitberger, U., Wieseler, B., Stammer, H., et al. (2002) Complications, comorbidity, and blood glucose control in type 2 diabetes mellitus patients in Germany - results from the CODE-2 study. Exp. Clin. Endocrinol. Diabetes 110, 10-16.

5. Health Canada (1997) Economic Burden of Illness in Canada. Cat. No. 1993 H21-136/193E. Laboratory Centre for Disease Control, Ottawa.

6. Hogan, P., Dall, T., and Nikolov, P. (2003) Economic costs of diabetes in the U.S. in 2002. Diabetes Care 26(3), 917-932.

7. Caro, J.J., Ward, A.J., and O'Brien, J.A. (2002) Lifetime costs of complications resulting from type 2 diabetes in the U.S. Diabetes Care 25, 476-481.

8. O'Brien, J.A., Shomphe, L.A., Kavanagh, P.L., Raggio, G., and Caro, J.J. (1998) Direct medical costs of complications resulting from type 2 diabetes in the U.S. Diabetes Care 21, 1122-1128.

9. Statistics Canada (2003) Canadian Community Health Survey (CCHS). http://www.statcan.ca/english/survey/other /canforgen.htm.

10. Statistics Canada (1997) National Population Health Survey, 1996-7. Health Statistics Division. Public Use Microdata Files. Ottawa.

11. Canadian Fitness and Lifestyle Research Institute (1997) Physical Activity Monitor Survey.

12. Chen, Y., Dales, R., Krewski, D., and Breithaupt, K. (1999) Increased effects of smoking and obesity on asthma among female Canadians: the National Population Health Survey, 1994-1995. Am. J. Epidemiol. 150, $255-262$. 
13. Chen, Y., Dales, R., and Krewski, D. (2001) Asthma and the risk of hospitalization in Canada: the role of socioeconomic and demographic factors. Chest 119, 708-713.

14. Chen, Y., Dales, R., Tang, M., and Krewski, D. (2002) Obesity may increase the incidence of asthma in women but not in men: longitudinal observations from the Canadian National Population Health Surveys. Am. J. Epidemiol. 155, 191-197.

15. Chen, Y., Breithaupt, K., and Muhajarine, N. (2000) Occurrence of chronic obstructive pulmonary disease among Canadians and sex-related risk factors. J. Clin. Epidemiol. 53, 755-761.

16. Tang, M., Chen, Y., and Krewski, D. (2003) Gender-related differences in the association between socioeconomic status and self-reported diabetes. Int. J. Epidemiol. 32, 381-385.

17. Tang, M. and Chen, Y. (2000) Prevalence of diabetes in Canadian adults aged 40 years or older. Diabetes Care 23, 1704-1705.

18. Chen, Y., Dales, R., Stewart, P., Johansen, H., Scott, G., and Taylor, G. (2003) Hospital readmissions for asthma in children and young adults in Canada. Pediatr. Pulmonol. 36, 22-26.

19. Pyorala, K., Laakso, M., and Uusitupa, M. (1987) Diabetes and atherosclerosis: an epidemiologic view. Diabetes Metab. Rev. 3, 463-524.

20. Resnick, H.E. and Howard, B.V. (2002) Diabetes and cardiovascular disease. Annu. Rev. Med. 53, $245-267$.

21. Arvind, K., Pradeepa, R., Deepa, R., and Mohan, V. (2002) Diabetes \& coronary artery disease. Indian J. Med. Res. 116, 163-176.

22. Moreno, P.R. and Fuster, V. (2004) New aspects in the pathogenesis of diabetic atherothrombosis. J. Am. Coll. Cardiol. 44(12), 2293-2300.

23. Reaven, G., Abbasi, F., and McLaughlin, T. (2004) Obesity, insulin resistance, and cardiovascular disease. Recent Prog. Horm. Res. 59, 207-223.

24. McLaughlin, T., Allison, G., Abbasi, F., Lamendola, C., and Reaven, G. (2004) Prevalence of insulin resistance and associated cardiovascular disease risk factors among normal weight, overweight, and obese individuals. Metabolism 53(4), 495-499.

25. Shirai, K. (2004) Obesity as the core of the metabolic syndrome and the management of coronary heart disease. Curr. Med. Res. Opin. 20(3), 295-304.

26. Sowers, J.R. (2003) Obesity as a cardiovascular risk factor. Am. J. Med. 115(Suppl 8A), 37S-41S.

27. Abate, N. (2000) Obesity and cardiovascular disease. Pathogenetic role of the metabolic syndrome and therapeutic implications. J. Diabetes Complications 14(3), 154-174.

28. Must, A., Spadano, J., Coakley, E.H., Field, A.E., Colditz, G., and Dietz, W.H. (1999) The disease burden associated with overweight and obesity. JAMA 282(16), 1523-1529.

29. Alter, D.A., Iron, K., Austin, P.C., Naylor, C.D. and SESAMI Study Group (2004) Influence of education and income on atherogenic risk factor profiles among patients hospitalized with acute myocardial infarction. Can. J. Cardiol. 20(12), 1219-1228.

30. Booth, G.L. and Hux, J.E. (2003) Relationship between avoidable hospitalizations for diabetes mellitus and income level. Arch. Intern. Med. 163(1), 101-106.

31. Evans, J.M., Newton, R.W., Ruta, D.A., MacDonald, T.M., AND Morris, A.D. (2000) Socio-economic status, obesity and prevalence of Type 1 and Type 2 diabetes mellitus. Diabet. Med. 17(6), 478-480.

32. Nilsson, P.M., Johansson, S.E., and Sundquist, J. (1998) Low educational status is a risk factor for mortality among diabetic people. Diabet. Med. 15(3), 213-219.

33. Garber, A.J. (2000) Diabetes and vascular disease. Diabetes Obes. Metab. 2(Suppl 2), S1-S5.

\section{This article should be cited as follows:}

Mo, F., Pogany, L., Li, F.C.K., and Morrison, H. (2006) Prevalence of diabetes and cardiovascular comorbidity in the Canadian Community Health Survey 2002-2003. TheScientific WorldJOURNAL 6, 96-105. DOI 10.1100/tsw.2006.13. 


\section{BIOSKETCHES}

Frank Mo, PhD, MD, Centre for Chronic Disease Prevention and Control, Population and Public Health Branch, Health Canada. E-mail: Frank_Mo@hc-sc.gc.ca

Lisa M. Pogany, MSc, Centre for Chronic Disease Prevention and Control, Population and Public Health Branch, Health Canada.

Felix C.K. Li, MB BS, FRCPC, Centre for Chronic Disease Prevention and Control, Population and Public Health Branch, Health Canada.

Howard Morrison, MSc, PhD, Centre for Chronic Disease Prevention and Control, Population and Public Health Branch, Health Canada. 


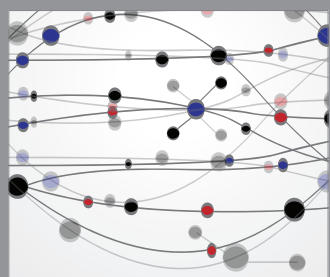

The Scientific World Journal
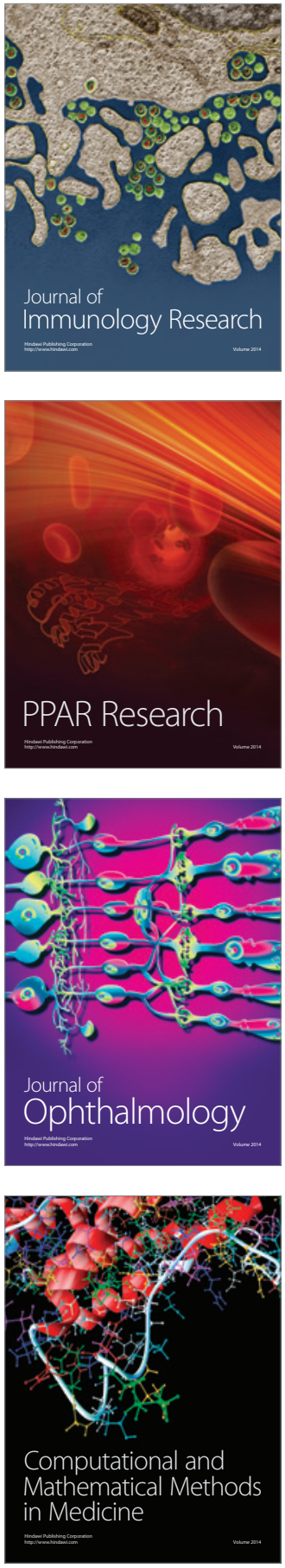

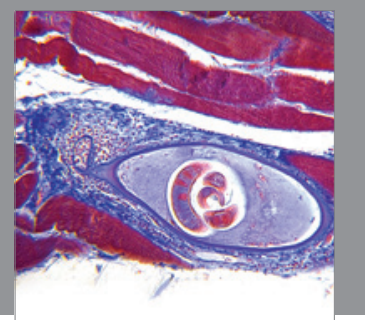

Gastroenterology

Research and Practice
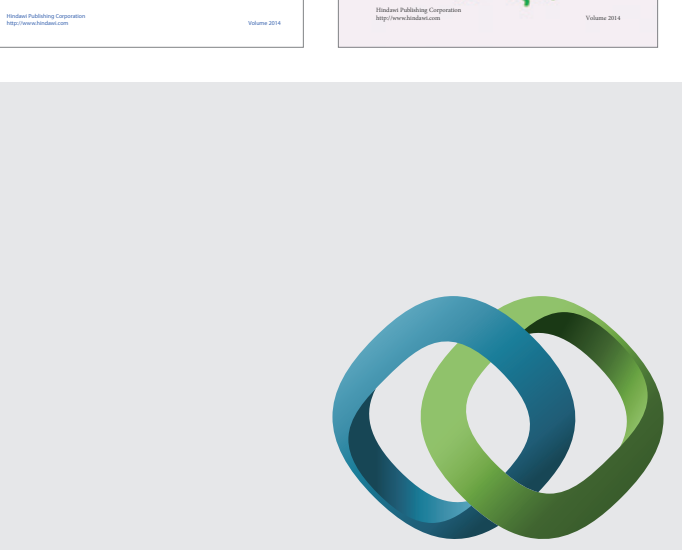

\section{Hindawi}

Submit your manuscripts at

http://www.hindawi.com
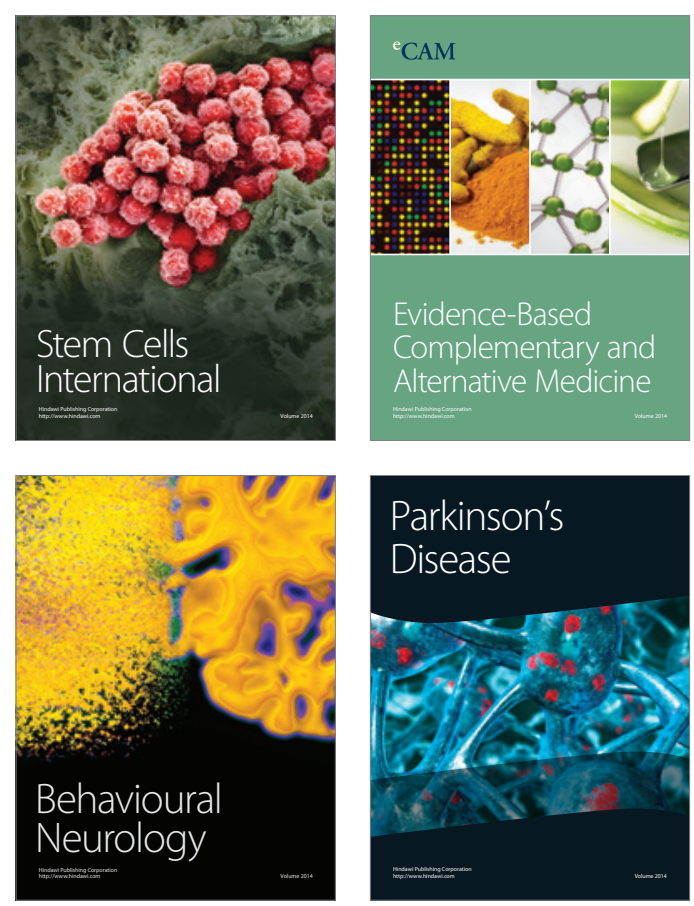

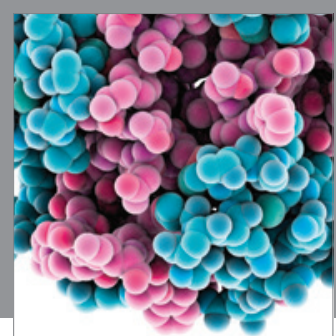

Journal of
Diabetes Research

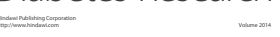

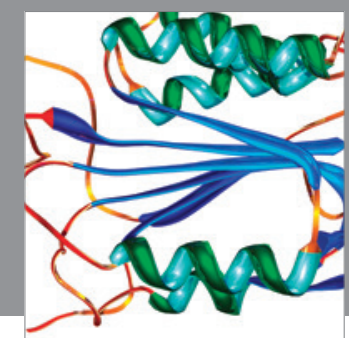

Disease Markers
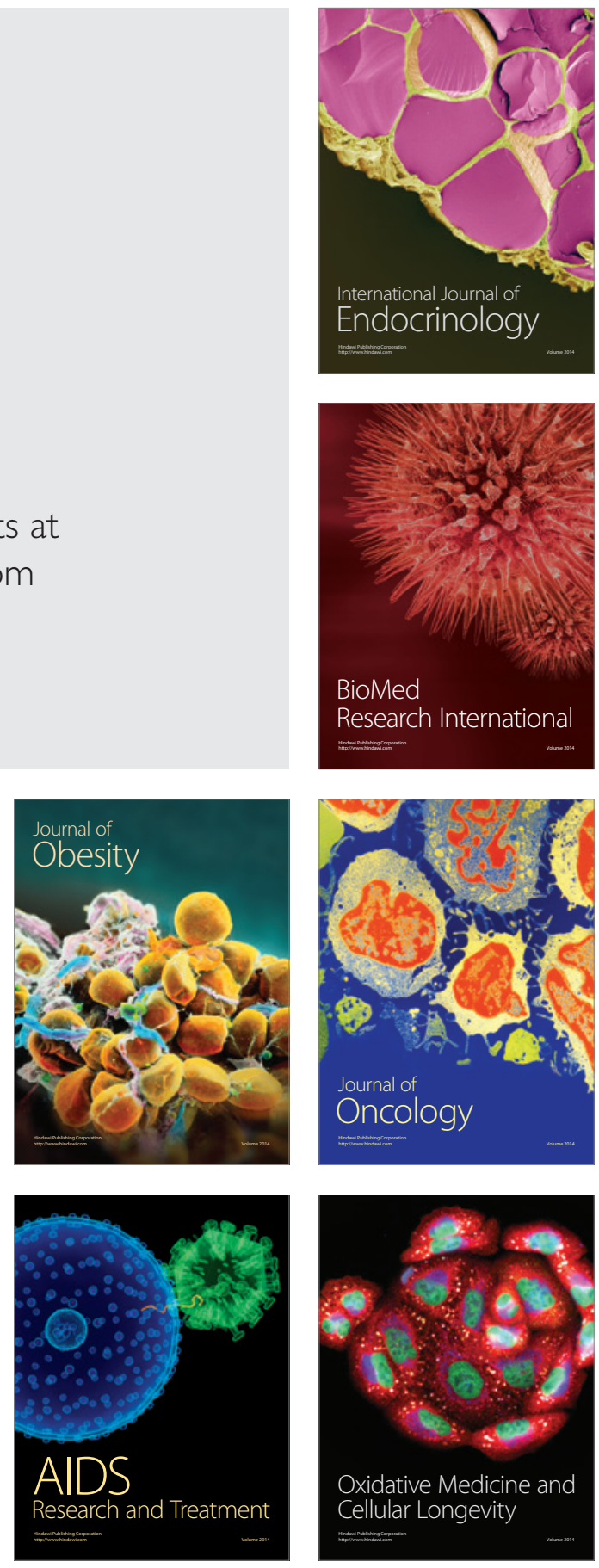